\title{
EDUCAÇÃO ESPECIAL: COMPREENDENDO A PRODUÇÃO DO CONHECIMENTO COM A TEORIA DA COMPLEXIDADE
}

\author{
Camyla ANTONIOLI ${ }^{1}$ \\ Sílvia Maria de Oliveira PAVÃO ${ }^{2}$
}

RESUMO: O artigo objetiva estabelecer relações entre a produção do conhecimento em educação especial e os métodos de pesquisa nessa área de estudos. Ao encontro do debate proposto e como fio condutor para uma análise qualitativa, a fundamentação teórica apresenta conhecimentos da Teoria da Complexidade (MORIN, 2000, 2005). A produção do conhecimento em educação especial cresce quantitativamente principalmente após a vigência das atuais políticas educacionais, como consequência disso, foi expandida a utilização de métodos de pesquisa. O debate proposto é descrito como um desafio, pois não se deixa por saciar, sendo assim compreendido como constante e emergente.

PALAVRAS-CHAVE: Pesquisa. Educação especial. Conhecimento. Complexidade.

\section{Introdução}

Entender como acontecem às forças que movem as produções de conhecimento no campo da educação especial requer situá-las na cultura, na história, na política, nas instituições acadêmicas e ainda na subjetividade. Ao longo da história a educação especial passou por processos de definição do público alvo, das conduções de trabalho, definições políticas e consolidação do campo como produtor de conhecimento.

Por volta de 1930, a educação especial estava limitada a instituições que desenvolviam práticas segregativas das pessoas com algum tipo de deficiências ou transtornos do desenvolvimento ou comportamentais. A normalidade era compreendida como um ideal de homem a ser cultivado, para isso, conhecimentos dos campos da saúde e psicologia perpassaram as ações de trabalho junto as pessoas que se encontravam a margem da norma. Na década de 1980, interesses políticos e de trabalho ganham força nos direcionamentos de instrução para as pessoas com deficiência.

\footnotetext{
${ }^{1}$ Especialização em Gestão Educacional. Mestranda. UFSM - Universidade Federal de Santa Maria. Santa Maria - RS - Brasil. 97105-900 - camyantonioli@gmail.com.

${ }^{2}$ Mestrado em Inovação e Sistema Educativo. UAB - Universidad Autónoma de Barcelona. Doutor em Educação. UAB - Universidad Autónoma de Barcelona. Professor adjunto. UFSM - Universidade Federal de Santa Maria. Santa Maria - RS - Brasil. 97105-900 - silviamariapavao@gmail.com.
} 
Movimentos sociais, coordenados por familiares e profissionais da área da educação especial também foram parte importante da história do campo.

Atualmente, ao se pensar sobre o público alvo da educação especial de imediato é referenciada a Política Nacional na Perspectiva da Educação Inclusiva (BRASIL, 2008), que define o público formado por pessoas com: deficiências, transtorno do espectro do autismo e altas habilidades/superdotação. A política supracitada é um dos principais documentos, que orienta práticas e fomenta debates na área da educação especial. Importante observar que as políticas educacionais desencadeiam eventos que impulsionam a produção de pesquisas, sendo que os estudos agregam conhecimentos a este campo do saber e possibilitam pensar sobre a visibilidade e direitos das pessoas público alvo.

O aumento da produção científica das universidades brasileiras é evidenciado nas publicações em periódicos científicos. Pensando nos aspectos organizacionais do artigo científico, esse possui certos elementos, como por exemplo, o método, que precisam ser evidenciado para que a essência deste seja constituída. Por método, encontram-se alguns autores que desenvolvem em teorias explicações que o definam (LÜDKE; ANDRÉ, 1986; TRIVIÑOS， 1987; GIL， 1991; MINAYO， 1994; CHIZZOTTI, 2006), observando-se um consenso no que tange a importância deste elemento organizacional para o desenvolvimento de estudos. Assim, na busca por compreender como as pesquisa em educação especial têm impactado enquanto campo produtor de conhecimento é lançado o seguinte questionamento: Em que medida o método de pesquisa é evidenciado nas produções científicas no campo da educação especial? E ainda, como o método enquanto orientador dos conhecimentos dentro da pesquisa é articulado às políticas educacionais e aos paradigmas no campo em questão?

Ao se propor o problema, foi tomado como caminhos condutores de possíveis respostas os estudos desenvolvidos por um grupo de pesquisadores na área da educação especial, cujas investigações são centradas na sistematização de um estado da arte do conhecimento produzido principalmente nas últimas duas décadas. Os estudos fundamentadores são creditados a: Gatti (2001), Vilela-Ribeiro, Benite e Lima-Ribeiro (2011), Marques et al. (2008), Vilela e Manzini (2009), Naujorks (2008), Manzini (2011), Jesus, Baptista e Victor (2006).

Considerando esses pressupostos ora apresentados o objetivo do estudo consiste em estabelecer relações entre a produção do conhecimento em educação especial e os métodos de pesquisa nessa área de estudos. Problematizações sobre a 
transdisciplinaridade de saberes também serão visíveis nesse estudo. O conhecimento produzido passa por transformações constantes que demandam solicitações diferenciadas à medida que são tecidas descobertas que ampliam o olhar do próprio homem direcionando visibilidades holísticas.

Para Morin (1999, p.73), há uma necessidade imprescindível de articulação dos saberes, pois a “[...] constituição de um objeto ao mesmo tempo interdisciplinar, polidisciplinar e transdisciplinar, permite, muito bem, criar a troca, a cooperação e a policompetência". A transdisciplinaridade apresentada pelo paradigma da complexidade quando explorada na educação oferece um suporte na construção do conhecimento multidimensional. Sendo assim, a transdisciplinaridade como a transpenetração de conhecimentos, motivando articulações, transformações e ações polirrelacionais, onde cada elemento liga-se e religa-se conforme o respeito e a observância da unidade na diversidade.

\section{Educação especial e a produção do conhecimento}

O problema de pesquisa surge de anseios oriundos das leituras, estudos e análises das produções científicas do campo da educação especial. Para Chizzotti (2006, p.81), “[...] o problema não resulta de uma afirmação prévia e individual, formulada pelo pesquisador e para a qual recolhe dados comprobatórios". Posto que o problema nasça em indagações que movimentam o pesquisador, por conta de estudos e experiências profissionais. Por encaminhamentos do problema norteador o método qualitativo tece esse estudo, sendo que em alguns momentos apresenta conduções bibliográficas.

A educação especial é o campo de conhecimento que abriga as pesquisas que foram supracitadas no momento introdutório, sendo que esses foram os encaminhamentos bibliográficos para o estudo. Ingressando no debate, Jesus e Baptista (2006, p.13) apresentam que a “[...] evolução da área nos últimos 20 anos, com evidente predomínio de uma perspectiva analítica que dá prioridade à inclusão escolar dos alunos com necessidades educacionais especiais no ensino comum". Historicamente, com influências do campo das ciências exatas, os estudos nas ciências humanas também eram realizados por conduções de pesquisas de carácter quantitativo com encaminhamentos experimentais. Gatti (2001), alerta para o fato de que com uma produção pequena, a pesquisa em educação especial, era realizada em grupos 
localizados e predominava a condução por pesquisas com enfoque “[...] psicopedagógico e temáticas como desenvolvimento psicológico das crianças e adolescentes processos de ensino e instrumentos de medida de aprendizagem". (GATTI, 2001, p.6).

Na pesquisa de Gatti (2001), intitulada "Implicações e perspectivas da pesquisa educacional no Brasil Contemporâneo", o objetivo condutor foi o de recuperar no tempo aspectos do desenvolvimento das pesquisas educacionais no Brasil, associandoos as conjunturas histórica-sociais. A autora apresenta um retrospecto histórico das pesquisas em educação especial, sendo destacadas, das passagens de sua investigação, as décadas de 1930 a 1990. É notável que muitas transformações acontecessem no percurso da história do Brasil, sendo esses sentidos e atravessados também nos espaços de pesquisa em educação especial. Os interesses por pesquisa foram também influenciados pelos paradigmas vigentes de cada época.

Para Morin (2005) a ciência não se limita a crescer, transforma-se, sendo ainda que há um problema prévio a todo acontecer de pesquisas, que são os paradigmas ou princípios que determinam e controlam o conhecimento científico. Por conta disso, o desenvolvimento da ciência não se efetua por acumulação dos conhecimentos, mas por transformação dos princípios que organizam o conhecimento.

A necessidade de compreender a educação, oferecida às pessoas público alvo da educação especial é premente, pois com transcorrer do tempo e dos estudos em ciências humanas a área foi se fortalecendo como campo de produção do conhecimento (NAUJORKS, 2008; GATTI, 2001; VILELA-RIBEIRO; BENITE; LIMA-RIBEIRO, 2011). Destaca-se que os debates e investigações são provenientes de diferentes áreas do conhecimento, mas em comum essas áreas possuem vivências junto as pessoas com deficiências, transtorno do espectro do autismo e altas habilidades/superdotação.

Identificaram-se diferentes necessidades de encaminhamentos metodológicos para responder aos problemas que originaram as pesquisas (VILELA; MANZINI, 2009; MANZINI, 2011). Dessa forma, transpassar o olhar para além de um principal tipo de pesquisa em detrimento de outros, foi um movimento significativo nas pesquisas em educação.

Nota-se que nas ciências humanas, neste caso referindo mais especificamente do campo da educação especial, atualmente a utilização de métodos qualitativos. Esse dado é corroborado por Chizzotti (2006) ao destacar a relação dinâmica entre o mundo real e o sujeito, a interdependência viva entre o sujeito e o objeto, o vínculo indissociável 
entre o mundo objetivo e a subjetividade do sujeito são elementos que compõem o método qualitativo.

Ao se abordar a pesquisa qualitativa também se destaca as orientações filosóficas que perpassam tal espaço, pois são expressas por pressupostos epistemológicos. As principais epistemologias, segundo Chizzotti (2006) são a fenomenologia e a dialética. A abordagem fenomenológica expressa à suposição de que o sujeito precisa ultrapassar as aparências para alcançar a essência dos fenômenos. Na dialética, há um destaque maior sobre a contradição dinâmica do fato observado e a atividade criadora do sujeito que observa, e também há a valorização da relação dinâmica entre sujeito e objeto.

Portanto, possibilidades de instigar o transformar da educação especial também podem ser movidas por pressupostos epistemológicos que conduzem o modo de fazer e analisar as pesquisas. Com detalhamento Marques et al. (2008) apresentam pesquisas realizadas no início do século XXI, que se diferenciavam em vários aspectos, mas um dos mais significativos foi o desenvolver de maior número de pesquisa com base em uma mesma perspectiva epistemológica que é a fenomenológica. Este fato não quer mostrar que a vertente epistemológica supracitada é melhor em relação a outras vertentes, se compreende que todas são importantes e também trazem elementos pertinentes, desafiadores e conhecimentos ao campo da educação especial. Entrementes o uso de uma perspectiva epistemológica não está relacionado unicamente a uma escolha subjetiva, mas, justamente ao problema que originou a pesquisa.

Deve ser observado que há um montante expressivo de pesquisas com base na epistemologia fenomenológica na área da educação. Marques et al. (2008) não aprofunda o esclarecimento deste resultado de sua pesquisa, apenas o descreve, talvez esteja neste ponto um elemento de interesse para futuras pesquisas. Afinal, como apresentam Vilela e Manzini (2009), fazer pesquisa é essencial, pois é por meio dela que o investigador desvenda o desconhecido ou se aprofunda em assuntos já existentes, contribuindo para o progresso da humanidade.

Os estudos de Gatti (2001), Vilela-Ribeiro, Benite e Lima-Ribeiro (2011), Marques et al. (2008), Vilela e Manzini (2009), Naujorks (2008) e Manzini (2011) apresentam uma análise da produção científica no campo da Educação especial. Conforme Naujorks (2008) é relevante à reflexão a respeito das produções no campo da educação especial, pois desta maneira é possível identificar avanços, tendências e as 
implicações práticas do conhecimento produzido, tanto para o cotidiano das escolas e instituições, quanto para a vida das pessoas envolvidas nestes processos.

As pesquisas na área da educação especial abrangem uma amplitude de debates e temáticas que têm contribuído não só para o avanço do conhecimento científico, como também têm produzido impactos em termos de pensar e fazer acontecer a educação, levando a compreensão de que os efeitos desses avanços podem ser traduzidos como mudanças paradigmáticas. Portanto, nesses caminhos encontra-se a complexidade da produção do conhecimento em educação especial, sendo que "[...] a complexidade não é a chave do mundo, mas o desafio a enfrentar, por sua vez o pensamento complexo não é o que evita ou suprime o desafio, mas o que ajuda a revela-lo, e às vezes mesmo a superá-lo.” (MORIN, 2006, p.8).

Tendo consciência do caminho tortuoso de se conseguir uma realização da prática transdisciplinar no seio da educação especial, ela precisa ser permanentemente buscada, para se chegar à autêntica razão de ser dessa modalidade de ensino, principalmente no sentido de fazer parte da formação da pessoa com deficiência. Importante perceber que a educação especial é parte do funcionamento da sociedade, determinando-a e sendo determinados por ela, por meio de constantes ações transformadoras, coletivas, conscientes e organizadas.

\section{Transdisciplinaridade na educação especial}

A transdisciplinaridade para/na educação trilha caminhos de evidenciar a educação especial como possível de relações com demais campos do conhecimento e de trabalho. A pessoa com deficiência percorre caminhos diversos em sua vida, em um deles encontra a educação e a educação especial. Importante compreender que os

processos relacionais e de intercambio de conhecimentos, mirados a transdisciplinaridade, acontecem cotidianamente entre a pessoa e a sua vida e por natural entre a pessoa e um espaço social com a escola.

Nas propostas educacionais a transdisciplinaridade se configura em uma vivência inclusiva, abrangente e transformadora das pessoas que dela participam, características que não existem nem são postas em prática de modo isolado, mas, ao contrário, se interpenetram e se influenciam simultaneamente. Segundo Morin (2000, p.4) " [...] o ensino por disciplina, fragmentado e dividido, impede a capacidade natural 
que o espírito tem de contextualizar", sendo que é essa capacidade que deve ser estimulada e desenvolvida pelo ensino, a de ligar as partes ao todo e o todo às partes.

Estabelecer um diálogo entre as diferentes áreas do conhecimento é um movimento necessário para o acontecimento da transdisciplinaridade. Os caminhos entre os diferentes campos do conhecimento se tornam mais tênues, o problema que atinge a educação especial é se essas relações podem também ser percepcionadas, vivenciadas nos métodos de pesquisa. Como possibilidade positiva a essa questão, Gatti (2001), Vilela-Ribeiro, Benite e Lima-Ribeiro (2011), Marques et al. (2008), Vilela e Manzini (2009), Naujorks (2008), Manzini (2011) e Jesus, Baptista e Victor (2006) de maneira sutil e sem mencionar uma só vez a palavra transdisciplinaridade apresentam que a educação especial como campo produtor de conhecimento é SIM aceitável a relações com outros campos do saber. Reflexos das tentativas e bem sucedidas relações transdisciplinares são visíveis nas produções científicas por meio das conduções dos métodos de pesquisa.

O conhecimento fragmentado, principalmente da realidade não satisfaz as necessidades fundamentais dos elementos ativos da sociedade (MORIN, 1999, 2000, 2001). Problematizar o processo que integre reciprocamente as várias disciplinas e campos de conhecimento, rompendo as estruturas de cada uma delas, é uma tarefa que demanda um moroso movimento. Para Morin (2001, p.288):

Fala-se de interdisciplinaridade, mas por toda a parte o princípio da disjunção continua a separar às cegas. Aqui e ali, começa-se a ver que o divórcio entre cultura humanista e a cultura científica é desastroso para ambas, mas os que se esforçam para estabelecer a ponte entre elas continuam a ser marginalizados e ridicularizados.

Sociedade esta que tem notáveis influências de ordem reprodutivista, que tem refletido no saber parcelado, na profissionalização, relações de trabalho e nas formas sistematizadas do conhecimento. Para tanto, na educação especial se é sabido que um dos focos de tal educação é tornar os aprendizados expressivos para as pessoas/estudantes, com o objetivo de auxiliá-los a integrar os conhecimentos dentro de si e atribuir sentido ao mundo em que se inserem e à maneira como nele atuam.

Em uma corrente do mundo moderno o trabalho não disciplinar, prevendo pontes entre as diferentes áreas do saber, tornou-se um imperativo emergente. A produção do conhecimento esta relacionado à reestruturação produtiva do próprio modo de conduzir as produções dos novos conhecimentos: a influência das novas tecnologias 
e com isto, a necessidade de diálogo entre as diversas áreas do conhecimento e também métodos de validar cientificamente esses conhecimentos. Os meios tecnológicos são aliados a disseminação e do acesso ao saber de modo rápido e abrangente ressaltando a noção de que o conhecimento se torna cada vez mais complexo. Em concordância, o pensamento complexo em sua multidimensionalidade, “[...] comporta em seu interior um princípio de incompletude e incerteza.” (MORIN, 1996, p.177).

A transdisciplinaridade é um avanço na construção de uma nova visão social, que leva em conta os avanços científicos e os desafios do mundo contemporâneo. Existe uma gama de diferentes entendimentos sobre o termo transdisciplinaridade. Profissionais das mais diversas áreas têm se debruçado sobre os termos. Em educação, ele é visto como um caminho viável para a construção do conhecimento global, numa época em que os saberes surgem e se acumulam de forma vertiginosa.

\section{O humano das ciências, as ciências humanas}

Ao olhar retrospectivamente para a produção do conhecimento no campo da educação especial, cabem as indagações: afinal, tudo já foi pesquisado? O que pesquisar de novo, para acrescentar, contribuir para a produção do conhecimento? Destas questões podem surgir diferentes hipóteses. Nesta pesquisa a hipótese proposta é que muitos conhecimentos ainda podem e serão produzidos no campo da em questão

O trabalho de Jesus e Baptista (2006) apresenta um panorama de produção diversificado e abrangente. Ao realizarem uma análise para a organização de um determinado evento, estabeleceram um conjunto de quatro diferentes áreas temáticas.

A primeira diz respeito ao campo das políticas públicas em educação especial. A segunda categoria acolhe as temáticas relativas à instituição escolar, práticas pedagógicas, processos de inclusão/exclusão escolar e formação de profissionais da educação. $\mathrm{O}$ terceiro grupo de estudos aborda perspectivas teóricas e análise de paradigmas com vistas a fundamentar questões de ordem política, pedagógica e filosófica. O outro grupo optou por (re)visitar a temática das abordagens teórico-metodológicas, de forma a pôr em questão as dificuldades, desafios e alternativas que se colocam aos pesquisadores (JESUS; BAPTISTA, 2006, p.17).

Importante observar que as áreas supracitadas esclarecem o que tem sido produzido na área da educação especial no Brasil. Isso se deve ao conjunto de análises 
com uma representatividade teórica e de lugar que abrange diferentes pesquisadores que atuam nas mais diversas instituições de ensino do país.

As interrogações sobre o conhecimento até então construído no campo da educação especial ainda seguem emergentes. Nesse ponto, Morin (2000) convida a pensar sobre a necessidade de destacar, em qualquer processo educacional, as grandes interrogações sobre as possibilidades de conhecer "[...] pôr em prática as interrogações constitui o oxigênio de qualquer proposta de conhecimento.” (MORIN, 2000, p.31).

Importante debater sobre a expressão "ciências humanas", o humano, o ser e estar no mundo do humano. Em que por referência ao humano se expressa que os do passado foram, os do presente são e os do futuro, a esses se deixa a opção de escolha. $O$ que integra e compõe o termo "ciências" junto as expressões humanas, afinal estas duas por si só já são compostas de múltiplos significados. Ao termo ciências expresso assim se reporta ao acontecer de conhecimentos, a partir de discursos diversos sobre o estar no mundo do ser humano.

O acontecer da produção do conhecimento nas ciências humanas é assim permeado pelas subjetividades, as diversidades, os contextos sociais, entre outros elementos que assim fazem parte do humano. A complexidade de fazer pesquisas nas ciências humanas está justamente neste ponto, pesquisar com e para seres humanos. A própria mudança no mundo da ciência aponta para uma nova necessidade do homem conhecer e aprender a trabalhar com relativizações, isto é, com as incertezas por meio do que ainda está se elaborando, do já elaborado e de projetos de descobertas.

Ao se retornar a hipótese de resposta para pergunta anteriormente apresentada, que em seu constante movimento de fazer ciências, de produzir conhecimentos as pesquisas em ciências humanas, e neste estudo focando nas pesquisas conduzidas na educação especial, que seguem com seus constantes e emergentes debates. Morin (2000, p.31) convida a pensar sobre "[...] o conhecimento do conhecimento, que comporta a integração do conhecedor em seu conhecimento, deve ser, para a educação, um princípio e uma necessidade permanentes".

A educação especial segue se transformado e transformando o acontecer das ciências. Assim foi no passado, como pode ser observado nas pesquisas apresentadas no início desse estudo, como está acontecendo no presente, em grupos de estudos, projetos de pesquisas, instituições de ensino e ainda nos desejos de muitos pesquisadores no seguimento de investigações, descobertas e (re)pensares sobre as pessoas com deficiências, transtorno do espectro do autismo e altas habilidades/superdotação. 
Ao encontro do debate sobre a visão transdisciplinar, essa considera o ser humano como um ente multidimensional com características biológicas, psíquicas, sociais, afetivas e racionais. Assim, importante olhar a humanidade considerando o direito a uma vida digna e plena a todos, sua identidade, a necessidade de convívio com o outro e a importância da diversidade existente em cada um. Para Morin (2000) essa realidade social é multidimensional e por isso é necessário contextualizar todos os dados.

Através da educação especial, com viés não somente disciplinar, é conhecida a diversidade educacional e humana. Assim, sendo reconhecida a importâncias do multiculturalismo, a existência de diferentes estilos cognitivos e maneiras diferentes (e não inferiores) de se construir o conhecimento e o respeito às pessoas público alvo da educação especial, bem como, as pessoas que trabalho para que essa aconteça.

\section{Considerações}

$\mathrm{O}$ acontecer das pesquisas em educação especial ao longo dos anos percorreu dois caminhos principais: um focando os estudos experimentais com método quantitativos e outro referente aos estudos qualitativos. Dentro dos dois caminhos apresentados, bifurcam-se outros rumos, estes que conduzem de forma mais específica a maneira pela qual se encontrou o método apropriado a responder o problema de pesquisa. Assim, destaca-se que cada pesquisa necessita de um olhar metodológico muito particular, pois é este que lhe possibilitará responder ao problema norteador.

Ao investigar sobre o conhecimento produzido em educação especial compreende-se que ao longo dos anos tem ocorrido uma intensificação da produção de pesquisas, que por consequência movimento a produção de novas problematizações e possíveis transformações de paradigmas. A possibilidade de se olhar por diferentes ângulos, problematizar, a realidade educacional instiga movimentos de mudança no profissional da educação, pois estes veem outras formas de orientar seu trabalho.

Os conhecimentos têm papel relacional entre o homem e o mundo, por intermédios destes acontecem as transdisciplinaridades de conhecimento entre a educação e o social, respondendo as suas perspectivas históricas e culturais. Por transdisciplinaridade compreende-se também a presença e importância para a produção do conhecimento dos conflitos, antagonismos e relações de forças que se estabelecem 
entre os epistemologias de estudos, grupos sociais, campos de pesquisa e áreas do conhecimento.

Importante compreender que a Teoria da Complexidade tem como ponto de partida a articulação dos saberes numa proposta transdisciplinar. Assim, sua base epistemológica considera as totalidades, ligando os saberes, promovidos pela excessiva especialização e fragmentação, no caso da Educação Especial a união de saberes vem ao encontro de potencializar e produzir conhecimentos enriquecedores em benefício da educação de pessoas com deficiências, transtorno do espectro do autismo e altas habilidades/superdotação.

Quanto ao problematizar as pesquisas produzidas em educação especial, é destacado que este processo ainda segue emergente, afinal o conhecimento está sempre em constante acontecer. Assim, os caminhos apontados por esta pesquisa seguem como um desafio emergente e relevante aos posteriores estudos.

\title{
SPECIAL EDUCATION: SPECIAL EDUCATION: UNDERSTANDING THE KNOWLEDGE PRODUCTION USING THE THEORY OF COMPLEXITY
}

\begin{abstract}
This paper discusses the relationships between the production of knowledge in special education and the methods of research in this area of studies. Converging towards the proposed discussion, and as a way that leads to a qualitative analysis, we present a theoretical background using the Complexity Theory (Morin, 2000, 2005). The production of knowledge in special education has been increasing especially because the implementation of the current educational policies, and as a result, the use of research methods has been expanded. The proposed discussion is depicted as a challenge; because it does not finish with this paper; and is understood as a topic which has always been in vogue, which is immediate and necessary.
\end{abstract}

KEYWORDS: Research. Special education. Learning. Complexity.

\section{REFERÊNCIAS}

BRASIL. Ministério da Educação. Política nacional de educação especial na perspectiva da educação inclusiva. 2008. Disponível em:

<http://portal.mec.gov.br/seesp/arquivos/pdf/politica.pdf>. Acesso em: 07 dez. 2013.

CHIZZOTTI, A. Pesquisa qualitativa em ciências humanas e sociais. Petrópolis:

Vozes, 2006.

GATTI, B. Implicações e perspectivas da pesquisa educacional no Brasil

Contemporâneo. Cadernos de Pesquisa, São Paulo, n.113, p.65-81, 2001. 
GIL, A. C. Como elaborar projeto de pesquisa. 3.ed. São Paulo: Atlas, 1991.

JESUS, D. M.; BAPTISTA, C. R. Educação especial, pesquisa e inclusão escolar: breve panorama de algumas trajetórias, trilhas e metas no contexto brasileiro. In: JESUS, D. M.; BAPTISTA, C. R.; VICTOR, S. L. (Org.). Pesquisa e educação especial: mapeando produções. Vitória: Editora da Universidade Federal do Espírito Santo, 2006. p.203-218.

.; VICTOR, S. L. (Org.). Pesquisa e educação especial: mapeando produções. Vitória: Editora da Universidade Federal do Espírito Santo, 2006.

LÜDKE, M.; ANDRÉ, M. E. D. A. Pesquisa em educação: abordagens qualitativas. São Paulo: EPU, 1986.

MANZINI, E. J. Tipo de conhecimento sobre inclusão produzido pelas pesquisas. Revista Brasileira de Educação Especial, Marília, v.17, n.1, p.53-70, 2011.

MARQUES, L. P. et al. Analisando as pesquisas em educação especial no Brasil. Revista Brasileira de Educação Especial, Marília, v.14, n.2, p.251-272, 2008.

MINAYO, M. C. S. O desafio do conhecimento científico: pesquisa qualitativa em saúde. 2.ed. São Paulo: Hucitec-Abrasco, 1994.

MORIN, E. Articular os saberes. In: ALVES, N.; GARCIA, R. L. O sentido da escola. Rio de Janeiro: DP\&A, 1999. p.65-80.

. Ciência com consciência. Rio de Janeiro: Bertrand Brasil, 1996.

. Ciência com consciência. Edição revista e modificada pelo autor. 8.ed. Rio de Janeiro: Bertrand Brasil, 2005.

Introdução ao pensamento complexo. Porto Alegre: Sulina, 2006.

O método 4. As ideias. Porto Alegre: Sulina, 2001.

Os sete saberes necessários à educação do futuro. 2.ed. São Paulo: Cortez; Brasília: UNESCO, 2000.

NAUJORKS, M. I. Análise preliminar da pesquisa em educação especial e inclusão educacional na ANPEd Sul. Revista de Educação Especial, Santa Maria n.32, p.301308, 2008.

VILELA, F. A.; MANZINI, E. J. Tipos de pesquisas: enfoque na educação especial. Revista de Iniciação Científica da FFC, Marília, v.9, n.3, p.285-292, 2009.

VILELA-RIBEIRO, E. B.; BENITE, A. M. C.; LIMA-RIBEIRO, M. S. Análise cienciométrica em educação especial: tendências e importância nos últimos 60 anos. Revista de Educação Especial, Santa Maria, v.24, n.40, p.285-304, 2011.

TRIVIÑOS, A. N. S. Introdução à pesquisa em ciências sociais: a pesquisa qualitativa em educação. São Paulo: Atlas, 1987. 